\title{
Towards Specialized Engineering Majors Based on Distributed e-Learning
}

\author{
Shahryar Rahnamayan \\ Faculty of Engineering and Applied Science, University of Ontario Institute of Technology (UOIT), Canada \\ shahryar.rahnamayan@uoit.ca
}

\section{INTRODUCTION}

Nowadays, we are faced with specialized job markets. The trend towards employing expert PhDs in very narrow research areas started about one or two decades ago. You rarely visit a job posting demands for a $\mathrm{PhD}$ without specifying any expertise in a related field. This trend is visible for both academic and industrial positions (research development sectors). Recently, we experience the same transition from general topics to specific ones for M.Sc. and M.Eng. degrees as well; exploring job hunting web sites clearly confirms the trend toward the specialized majors. Predicting the similar situation for B.Sc. holders' job markets, would not be unrealistic for the fast approaching decades. Just to mention an example, these days, jobs are offered to software engineers who are expert in network programming, security, database management, simulation, and etc. But as we know, a typical software engineering student just passes one threecredit course for each above mentioned topics during fouryear academic program. It seems, in order to tailor students' competence with job market's demands, we need to customize engineering majors accordingly. Course sharing could be one of the reasonable practical solutions.

\section{Course Sharing System}

Offering specialized courses for each specific program would be a viable solution, but it is hard or sometimes even unpractical for many universities with a comprehensive list of programs. Many faculty members are required for such majors and it would be unaffordable for universities. Utilizing a Distributed e-Learning system can be a novel solution in this regard; this could be implemented in provincial, national (among Canadian universities), and/or even international levels. By this way, universities can share professors with variant expertise, and therefore professors can offer their courses in a distributed manner. The paper focuses on engineering majors as a case study, but the main idea is extendable to other sciences properly. Schematic structure of a course distributed system based on provincial and national coordinators is presented in Fig. 1. For each province, a Local Coordinator is assigned, and National Coordinator is responsible for the country-wide coordinations. The variant architectures of learning technology systems can be investigated, such as, knowledge-based, interactive, or distributed e-learning [1], [2].

\section{Advantages And Challenges}

The main advantages of course sharing among the universities could be 1) reducing teaching costs, 2) sharing distributed

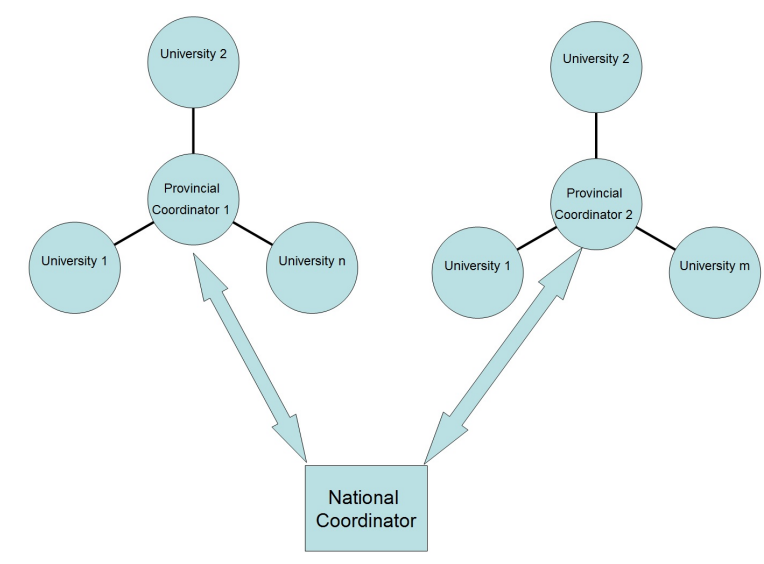

Fig. 1. Schematic structure of a course distributed system based on provincial and national coordinators.

expertise and supporting a national academic uniformity, 3) providing a comprehensive course variety for students, 4) supporting the possibility of offering specialized majors, 5) increasing the chance of research collaborations among the universities, 6) supporting a sort of teaching load balancing, 7) possibility of awarding multi-university degrees.

Some challenges are predictable as well, such as 1) objection of well-known universities regarding any kind of uniformities, 2) accounting complexities, 3) long distance learning difficulties, 4) complications related to providing a national distributed e-learning system among heterogenous academic systems. Furthermore, 7) specializing the majors leads on decreasing the job-major matching opportunities.

\section{CONCLUDING REMARKS}

Specialized majors based on a distributed e-learning system can provide many valuable assets for the national or even international wide universities in future, although, there are some challenging problems which should be addressed properly. The author proposes an evolutionary-based development for the system which hopefully will attract other universities to join in an approaching future.

\section{REFERENCES}

[1] Claus Pahl, Architecture Solutions for E-Learning Systems, IGI Global, 2008, ISBN: 9781599046334.

[2] Lester Gilbert, Veronica Gale, Principles of e-learning systems engineering, Chandos, 2007, ISBN:1843342901. 